\title{
Gay, Straight, or Somewhere in Between: Accuracy and Bias in the Perception of Bisexual Faces
}

\author{
Jonathan Y. C. Ding • Nicholas O. Rule
}

Published online: 12 January 2012

(C) Springer Science+Business Media, LLC 2012

\begin{abstract}
Sexual orientation can be accurately identified from photos of faces, but previous work has focused exclusively on straight versus gay and lesbian individuals. Across three studies, the current work investigated the facial perception of bisexual men and women, a less socially salient category. Although participants could identify straight and gay men at above-chance levels in a trichotomous categorization task, bisexual men were categorized only at chance (Study 1). Participants perceived bisexual men to be significantly different from straight men, but not gay men (Study 2). Similarly, whereas bisexual and lesbian women were not rated differently, both groups were distinguishable from straight female targets (Study 3). These findings suggest a straight-non straight dichotomy in the categorization of sexual orientation.
\end{abstract}

Keywords Bisexuality - Social cognition - Nonverbal behavior - Sexual orientation * Person perception

Individuals constantly make snap judgments of others in daily life (see Ambady and Rosenthal 1992). These judgments are made accurately and intuitively (Ambady et al. 2000). Sex (Brebner et al. 2009), age (Wright and Stroud 2002), and race (Richeson and Trawalter 2005) are some of the characteristics that individuals can identify with minimal effort. Many other qualities, such as how threatening a person is, can be perceived and encoded unconsciously and even subliminally (e.g., Bar et al. 2006; Choi et al. 2005).

In addition to the physical, unambiguous characteristics listed above, aspects of a person that are perceptually ambiguous can also be apprehended with ease. A person's sexual orientation, for example, can be inferred quickly, accurately, and automatically (Rule et al. 2009a). Making an inference of another's sexual orientation is likely dependent on a myriad of cues. A person's gait (Johnson et al. 2007), speech (Levon 2007; Smyth et al. 2003), clothing (Rudd 1996), eye gaze (Nicholas 2004), or even the pronunciation of a

J. Y. C. Ding · N. O. Rule $(\square)$

Department of Psychology, University of Toronto, 100 St. George Street, Toronto, ON M5S 3G3,

Canada

e-mail: rule@psych.utoronto.ca 
single syllable (Smith et al. 2008) all serve as indicators of sexual orientation. This ability is useful. For example, it allows gay individuals to identify ingroup members without needing to publicly disclose their own sexual orientation (Nicholas 2004; see also Rieger et al. 2010) and allows straight individuals to more efficiently find potential mates (Rule et al. 2011).

Although some of the aforementioned cues can be consciously altered (e.g., eye gaze length; Nicholas 2004), it appears that sexual orientation cannot be fully concealed through exerting effortful self-control (Sylva et al. 2010). To extend this idea further, Rule et al. (2008) found that participants were able to accurately judge targets' sexual orientations based on grayscale photos of the face alone. Furthermore, judgments of sexual orientation based only on facial features, such as the eyes and the mouth-areas more likely to be outside of a person's attention and control (Ekman and Friesen 1969)_-were also judged at above-chance levels. In other words, faces convey an individual's sexual orientation. This information is readily perceived by others and extracted automatically from a target's facial appearance (Rule et al. 2009b).

To date, previous research has only investigated the differences between the perceptions of gay and straight individuals. It is thus unclear whether such perceptions extend to less socially salient sexual orientations, such as bisexuality (see Weinberg et al. 1995, for a discussion on social attitudes toward bisexuality). In their seminal work on human sexual orientation, Kinsey et al. (1948) suggested that almost half of the male population exhibits bisexual behavior. Self-identified bisexual individuals are much rarer, with estimates from American surveys ranging from as low as $0.8 \%$ to about $4 \%$ (Chandra et al. 2011; Janus and Janus 1993; Laumann et al. 1994).

The prevalence and construction of bisexual behavior and identity is a topic of much interest and debate. Kinsey et al. (1948) viewed sexual orientation as a continuum with bisexuality at the center. However, many people think of sexual orientation as a dichotomy, composed of gay and straight orientations (Weinberg et al. 1995). Some scholars have also suggested that bisexuality may be a transient stage, with bisexuals being either gay and lesbian individuals who have not accepted their sexuality, or straight individuals experimenting with or confused about same-sex relationships (for a review, see Blumstein and Schwartz 1977; Goode and Haber 1977; MacDonald 1981). Thus, it is possible that bisexual persons may not be perceived differently from gay and straight individuals.

Whereas much of the literature has focused on the nature and definition of bisexuality, the current work sought to investigate the accuracy of individuals' perceptions of bisexual men and women from their facial appearance. Thus, in Study 1, we examined participants' ability to distinguish bisexual men from gay and straight men in a categorization task. In Study 2, we investigated the perception of bisexual men on a continuum to see whether they are perceived to be more similar to gay or to straight men. Finally, in Study 3, we examined the accurate perception of bisexual women using the same method as in Study 2.

\section{Study 1}

\section{Method}

Photos of 45 gay and 44 straight men were borrowed from an in-house database of faces used in previous research (e.g., Rule and Ambady 2008; full-face condition). In addition, 41 photos of men who identified themselves as bisexual and were interested in dating either a man or a woman were downloaded from online dating websites. Search criteria required 
Table 1 Confusion matrix of participants' mean judgments in percentages for each of the three stimulus types (gay, straight, and bisexual) in Study 1 standard deviations

\begin{tabular}{lcclr}
\hline Stimulus type & \multicolumn{4}{l}{ Judgment type } \\
\cline { 2 - 5 } & Gay & Straight & Bisexual & Total \\
\hline Gay & $10(6)$ & $19(7)$ & $6(4)$ & 35 \\
Straight & $6(5)$ & $23(6)$ & $4(3)$ & 33 \\
Bisexual & $9(5)$ & $18(6)$ & $5(3)$ & 32 \\
Total & 25 & 60 & 15 & 100 \\
\hline
\end{tabular}

that the targets be Caucasian, between the ages of 18-30, and free of any facial hair or adornments. The images were standardized using the same parameters as those used in the creation of the gay and straight photo sets (see Rule et al. 2008). Profiles were culled from various geographically-distant major US cities; thus, no participants recognized any of the faces.

Sixty undergraduates $(n=41$ female) participated in exchange for partial credit in an introductory psychology course or for monetary compensation. ${ }^{1}$ Participants were instructed that they would be seeing a series of men's faces on a computer screen and that they should categorize each face according to the target's probable sexual orientation as gay, straight, or bisexual via key-press. The order of the presentation of the images was random and participants viewed the photos at a self-paced rate $(M=1,508 \mathrm{~ms}$, $\mathrm{SE}=80 \mathrm{~ms}$ ), though they were encouraged to make their decisions as quickly as possible without thinking about any one face too much.

\section{Results and Discussion}

Although the majority of previous research examining the accuracy of judgments of sexual orientation has analyzed the data using signal detection analysis, the trichotomous nature of the present categorizations rendered the data less suited to that method. The data were therefore analyzed using the unbiased hit rate developed by Wagner (1993). In essence, the analysis considers the correct categorizations of targets into each category (i.e., the hits) while scaling these values according to each participant's response tendencies. The resultant proportions are then arcsine transformed and submitted to significance testing against chance levels for each stimulus category (i.e., gay targets, straight targets, and bisexual targets).

Wagner's (1993) method also provides a means for constructing individually-based chance levels for each participant that account for the perceiver's unique distribution of categorizations. Specifically, chance is calculated as the probability of selecting a particular response given the proportion of categorizations made in a given category. Table 1 provides the confusion matrix of participants' mean responses as a percentage of the total number of stimuli. Values on the diagonal indicate the raw hit rates for each stimulus class and the off-diagonal values are the participants' miscategorization rates for the other stimulus types.

Participants' accuracy in categorizing men as gay, straight, and bisexual from their faces was tested by comparing each participant's unbiased hit-rate against the perceiver's individual chance level for each stimulus category. This yielded a measure of accuracy for each of the gay, straight, and bisexual targets. Table 2 reports the means and standard

\footnotetext{
${ }^{1}$ Male and female participants showed no significant differences in any of the studies reported in this work.
} 
Table 2 Means and standard deviations for participants' unbiased hit rates and chance levels for their categorizations of gay, straight, and bisexual men's sexual orientations in Study 1

\begin{tabular}{llllll}
\hline & \multicolumn{2}{l}{ Unbiased hit rate } & & \multicolumn{2}{l}{ Chance guessing rate } \\
\cline { 2 - 3 } \cline { 5 - 6 } & $M$ & SD & & $M$ & SD \\
\hline Gay & .12 & .09 & .09 & .05 \\
Straight & .26 & .07 & .20 & .06 \\
Bisexual & .06 & .04 & .05 & .03 \\
\hline
\end{tabular}

Values reported are those prior to arcsine transformation

deviations for the participants' unbiased hit rates and chance levels for each stimulus type. Paired $t$ tests between the participants' unbiased hit rates and chance accuracy scores were conducted to measure the statistical significance of their accuracy and Bonferronicorrected for multiple comparisons $(\alpha=.017)$. Accuracy for categorizing both gay $[t(59)=3.69, p<.001, r=.43]$ and straight $[t(59)=8.77, p<.001, r=.75]$ targets was significantly better than chance guessing. Categorizations of bisexual targets, however, were not significantly different from chance following Bonferroni correction: $t(59)=2.32$, $p=.024, r=.29$.

These data therefore suggest that although perceivers are capable of distinguishing gay and straight targets, as reported in previous work, they are less able to accurately categorize men describing themselves as bisexual. A key limitation of this study design, however, is that the trichotomous categorization of targets does not permit for an efficient measure of response bias. Thus, it is presently unclear whether bisexual targets may be inaccurately categorized as gay or as straight. Study 2 therefore sought to investigate the question of bisexuals' legibility further by asking participants to rate the targets' sexual orientations along a continuum.

\section{Study 2A}

\section{Method}

Each of the 130 processed photos used in Study 1 were shown in randomized order to 33 undergraduates $(n=27$ females; ICC $=.88,95 \%$ CI $[.85, .91])$ who received partial credit in an introductory psychology course or monetary compensation. The participants were instructed that they would be seeing a series of men's faces on a computer screen and that they should rate each face along a 7-point scale via key-press, ranging from 1 "Definitely gay" to 7 "Definitely straight" at a self-paced rate $(M=1,879 \mathrm{~ms}, \mathrm{SE}=108 \mathrm{~ms})$ as quickly and accurately as possible. No participant recognized any of the faces.

\section{Results and Discussion}

Due to the continuous nature of the participants' responses, we analyzed the data using sensitivity correlations (Rule et al. 2008). Thus, to assess the overall effect of sexual orientation on facial categorizations, we first correlated participants' judgments with a trichotomous vector representing the targets' actual sexual orientations: $-1=$ straight, $0=$ bisexual, and $1=$ gay. This resulted in a correlation coefficient $(r)$ for each 
participant, indicative of their overall accuracy in perceiving sexual orientation. These $r$ values were then converted to Fisher's $z$ scores for analysis and the results were converted back to $r$ values using the inverse of the Fisher transform.

Participants were significantly more accurate than chance $(r=.00)$ in their categorizations at $\alpha=.05$, as the 95\% confidence interval around the participants' mean sensitivity correlation did not include 0: $\bar{r}=.21 \mathrm{SD}=.12,95 \% \mathrm{CI}[.17, .25]$. As noted in Study 1, however, the accuracy of categorizing bisexual men may or may not contribute to this overall effect. Consequently, we decomposed the omnibus sensitivity correlation into three, Bonferroni-corrected $(\alpha=.017 ; 98.3 \%$ confidence interval) pair-wise comparisons. Similar to previous work, participants were able to distinguish between the gay and straight targets significantly better than chance: $\bar{r}=.26, \mathrm{SD}=.15,98.3 \%$ CI $[.20, .32]$. In addition, participants were able to distinguish between the straight and bisexual targets significantly better than chance, $\bar{r}=.19, \mathrm{SD}=.13,98.3 \% \mathrm{CI}[.13, .24]$; but not between the bisexual and gay targets, as the confidence interval contained $0: \bar{r}=.06, \mathrm{SD}=.17,98.3 \%$ CI $[-.01, .13]$.

We were also interested in the differences between the targets. We therefore conducted a second analysis in which we averaged across all of the participants' judgments for each target and compared the mean ratings for each of the three groups. A one-way ANOVA revealed a significant difference in the ratings among the 3 groups, $F(2,127)=17.61$, $p<.001, \eta_{\text {partial }}^{2}=.22$; see Fig. 1. Post hoc Scheffé tests indicated a difference between the ratings of straight men $(M=4.79, \mathrm{SE}=.11)$ and bisexual men $(M=4.15, \mathrm{SE}=.11)$, $p<.001$, in that straight male targets were rated significantly higher (i.e., more "straight" and less "gay") than bisexual men. Similarly, photos of straight men were also rated to be significantly more "straight" than that of gay men $(M=3.93, \mathrm{SE}=.11), p<.001$, replicating previous work (Rule et al. 2008). The Scheffé test did not reveal significant differences between the ratings of bisexual and gay male targets, however: $p=.38$.

These data therefore suggest that, although participants perceived bisexual men to be different from straight men, they were unable to distinguish between bisexual and gay targets. The bisexual targets were rated as non-significantly "straighter" than the gay targets, however. Given that sexual orientation is often considered to be a dichotomy of straight and non-straight identities (Weinberg et al. 1995), it is possible that the straight targets anchored the judgments, resulting in shifting standards that might have affected participants' judgments (Biernat and Manis 1994). Study 2B therefore tested the differences between gay versus bisexual, and straight versus bisexual male targets separately.

Fig. 1 Participants' mean sexual orientation ratings of gay, bisexual, and straight male faces along a continuum in Study $2 \mathrm{~A}$. Error bars denote one standard error around the mean

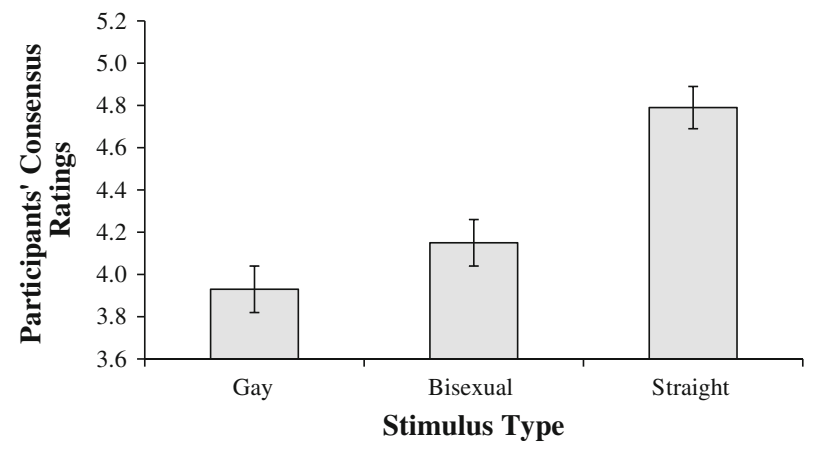




\section{Study 2B}

\section{Method}

Ninety undergraduates ( $n=73$ females) received partial credit in an introductory psychology course or monetary compensation for their participation. They were randomly assigned to two conditions, each using the same set of stimuli from Studies 1 and 2A. In both conditions, participants rated targets' faces in random order, using the same 7-point scale as in Study 2A. In one condition $(n=50$; ICC $=.90,95 \%$ CI $[.87, .93])$, participants rated only the bisexual and straight targets; in the other condition $(n=40$; ICC $=.86$, 95\% CI $[.81, .90])$, participants rated only the bisexual and gay targets. Both conditions were self-paced (overall response latency $M=2,114 \mathrm{~ms}$, SE $=71 \mathrm{~ms}$ ), though participants were encouraged to work as quickly and accurately as possible. No participant recognized any of the faces.

\section{Results and Discussion}

The data were analyzed as in Study 2A. Sensitivity correlations showed that participants were able to distinguish the straight from the bisexual targets significantly better than chance: $\bar{r}=.17, \mathrm{SD}=.15,95 \% \mathrm{CI}[.13, .20]$. Participants in the other condition, however, were not able to differentiate the gay and bisexual targets: $\bar{r}=-.01, \mathrm{SD}=.17,95 \% \mathrm{CI}$ $[-.07, .04]$. Thus, like the findings in Study $2 \mathrm{~A}$, participants were able to differentiate bisexual men from straight men but were unable to differentiate bisexual men from gay men.

Analysis at the level of targets showed similar effects. In the first condition, a significant difference was found between the perception of bisexual $(M=4.22, \mathrm{SE}=.09)$ and straight $(M=4.73, \mathrm{SE}=.07)$ targets: $t(83)=4.28, p<.001, r=.43$. In other words, straight targets were rated to be significantly more "straight" than bisexual targets, replicating the results of Study 2A. In the second condition, however, there was no significant difference between the ratings of bisexual $(M=4.46, \mathrm{SE}=.10)$ and gay $(M=4.40$, $\mathrm{SE}=.08)$ targets: $t(83)=0.29, p=.78$. Hence, the bisexual men were perceived to be just as "gay" as the gay targets, indicating that photos of bisexual male faces could not be reliably distinguished from that of gay male faces. These results, as well as those from Study 2A, therefore suggest that the inability of perceivers to accurately categorize bisexual men in Study 1 might have been due to miscategorizations of bisexual targets as gay rather than straight.

\section{Study 3}

Having established that bisexual men were rated differently only from straight men, we investigated whether a similar effect might be present among women. The sexual orientation of women has been considered to be more fluid and malleable than that of men (Baumeister 2000; Peplau 2003), and bisexuality is alleged to be both more common and more acceptable in women versus men (Eliason 2001; Herek 2002; Savin-Williams and Ream 2007). Study 3 thus sought to examine whether bisexual female targets are distinguishable from straight women and lesbian women. 
Method

Procedures followed those of Study 2A, with the exception that female targets were used instead of male targets. Photos of 40 lesbian women and 40 straight women were borrowed from a database of faces used in previous research (Rule et al. 2009a; full-face condition). In addition, 40 photos of self-identified bisexual women were downloaded from online dating websites and prepared in the same manner as the straight and lesbian women's faces (see Rule et al. 2009a).

Forty undergraduates $(n=23$ female; ICC $=.92,95 \%$ CI $[.90, .94])$ received partial credit in an introductory psychology course or monetary compensation. Participants were instructed that they would be seeing a series of women's faces on a computer screen and that they should rate each face along a 7-point scale via key-press, ranging from 1 "Definitely lesbian" to 7 "Definitely straight." The experiment was self-paced $(M=1,985 \mathrm{~ms}, \mathrm{SE}=107 \mathrm{~ms})$, though participants were encouraged to work as quickly and accurately as possible. No participants recognized any of the faces.

\section{Results and Discussion}

Sensitivity correlations showed that, overall, perceivers were able to distinguish the women based on their sexual orientations: $\bar{r}=.14, \mathrm{SD}=.08,95 \%$ CI $[.11, .18]$. Decomposition of this omnibus effect by pairwise comparisons of the three groups showed that lesbian and straight women were differentiated significantly better than chance, $\bar{r}=.18, \mathrm{SD}=.11$, 98.3\% CI $[.15, .21]$; and that bisexual and straight women were differentiated significantly better than chance, $\bar{r}=.19, \mathrm{SD}=.16,98.3 \% \mathrm{CI}[.14, .24]$; but that perceivers could not distinguish between lesbian and bisexual women: $\bar{r}=-.004, \mathrm{SD}=.11,98.3 \% \mathrm{CI}[-.04$, .03].

We next analyzed the mean ratings given to each target, as above. A one-way ANOVA showed a significant difference in the ratings of the three target types, $F(2,117)=7.99$, $p=.001, \eta_{\text {partial }}^{2}=.12$; see Fig. 2. Post hoc Scheffé tests revealed significant differences between the ratings given to straight women $(M=4.88, \mathrm{SE}=.07)$ versus lesbian women $(M=4.35, \mathrm{SE}=.15), p=.005$, replicating previous work (Rule et al. 2009a). In addition, straight and bisexual women $(M=4.30, \mathrm{SE}=.11)$ significantly differed: $p=.002$. However, the difference between bisexual and lesbian women was not significant, $p=.96$, nor were the means in the expected direction. Thus, the pattern of judgments of sexual orientation for women mirrors that of men: bisexual women were judged to look different from straight women, but were seen as no different than lesbian targets.

Fig. 2 Participants' mean sexual orientation ratings of lesbian, bisexual, and straight female faces in Study 3. Error bars denote one standard error around the mean

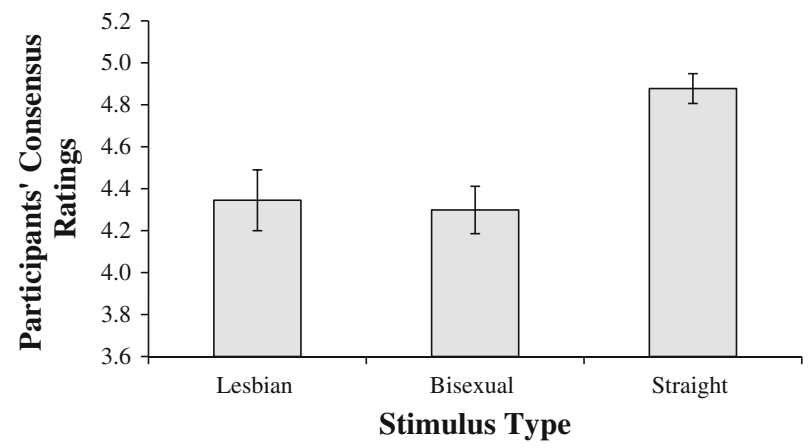




\section{General Discussion}

Individuals perceive group memberships automatically, including sexual orientation (Macrae and Bodenhausen 2001; Rule et al. 2009b). In Study 1, we found that although both gay and straight men could be accurately categorized according to their sexual orientations, bisexual men were not identified at higher-than-chance levels. In Study 2, we found that bisexual men were consistently perceived to be different from straight men; however, there were no differences between the ratings of gay and bisexual men, even when straight targets were not included in the experiment. These results suggest that bisexual targets were likely miscategorized as gay in Study 1. Finally, in Study 3, we found similar results for female targets: bisexual targets were distinguished from straight but not lesbian targets. The pattern of results across these studies therefore consistently suggests that although bisexual men and women can be differentiated from straight individuals, they are not perceived to be different from gay-lesbian people.

The perception of information from nonverbal cues has often been attributed to evolutionary advantages (e.g., Gibson 1979; Haselton and Funder 2006; McArthur and Baron 1983; Schaller 2008; Sedikides and Skowronski 2009; Zebrowitz and Montepare 2006). Some have suggested that perceiving others' sexual orientation can benefit mate selection (see Miller and Todd 1998; Thornhill and Gangestead 1996). For example, to assess the potential for mating, it may be beneficial for heterosexual women to determine the sexual orientation of a man they meet. Likewise, to assess potential competition for mates, it may be helpful for heterosexual men to determine the sexual orientation of the same man (Wright and Sladden 2003). Similarly, homosexual individuals would benefit from an ability to identify ingroup members that have not openly revealed their sexual orientations and to distinguish these people from outgroup members, who may pose a threat (Nicholas 2004; Rieger et al. 2010). In support of this idea, gay men and lesbian women have been found to be better judges of sexual orientation (Rule et al. 2007; see also Ambady et al. 1999; Rieger et al. 2010).

Yet, if social perception functions entirely in terms of mates and assessing competition, one might expect bisexuals to be seen as more similar to straight individuals, given that their interest in the opposite sex renders them potential mates for the members of one sex and potential competition for the members of the other sex. Rather, the results of the present study showed that bisexuals were consistently mistaken as gay and there were no sex differences in judgments, neither at the level of targets nor perceivers. Instead, both male and female participants rated the groups dichotomously, illustrating a difference in the perception of straight and non-straight targets; but showed no difference in the perception of gay and lesbian versus bisexual targets. This could be due to a few mutually non-exclusive causes: there may be no differences between the faces of bisexual versus gay and lesbian individuals; participants may not be paying adequate attention to the subtle cues that differentiate bisexual from gay and lesbian faces; or, alternatively, participants may be relying excessively on the socially salient straight-gay dichotomy to make their decision (Weinberg et al. 1995). Further studies should thus investigate the motivations and bases for making judgments of sexual orientation, especially with regard to categories outside of the perceived gay-straight divide.

It would also be interesting to observe how perceivers arrive at such conclusions. Previously, it has been found that accurate judgments of sexual orientation can be made on the basis of the targets' individual features, such as hairstyle, eyes without brows, and mouth (Rule et al. 2008, 2009a). Although we have not investigated the perception of 
specific features in the present study, given that these judgments are highly reliable (Rule et al. 2008) and that bisexual versus gay and lesbian targets are not differentiated, it seems plausible that perceivers might arrive at similar judgments even if only a specific feature of the face is shown.

Faces are not only indicative, they are also predictive (e.g., Collins and Zebrowitz 1995; Harker and Keltner 2001; Mueller and Mazur 1996; Rule and Ambady 2011; Zebrowitz and McDonald 1991). In particular, sexual identity is often considered to be fluid (Cass 1984), and as many as a quarter of bisexual or lesbian women report a change in their sexual orientation over a period of 5 years (Diamond 2003). Given that perceptions of targets in each category overlap at least somewhat with those from other categories, it is possible that perceivers' judgments of sexual orientation may predict an individual's future, ultimate, or predominant self-identification. Furthermore, in addition to its predictive powers, social perception also influences behavior, and being perceived to be gay or straight by others could affect the development of sexual orientation (Ambady et al. 2000; Rieger et al. 2008; Rosenthal and Jacobson 1968). Consequently, longitudinal studies should examine the predictive and potentially causal powers of perceivers' judgments of sexual orientation.

Naturally, our findings must also be interpreted with some caution so as not to draw conclusions that are beyond these specific data. Differences in appearance are insufficient to make an argument about the nature of bisexuality or bisexual individuals. Indeed, we make no claims as to the genesis of bisexuality and its relationship to facial appearance, as the present data are not in a position to speak on these topics. Instead, given the amount of information that is contained in the face (Zebrowitz 1997), future research should work to better delineate the cues that signal a person's sexual orientation, and what that means for both the perceiver and the perceived.

Another limitation of this work is that the photos were downloaded from online dating sites. Given the nature of online profiles, bisexual individuals may not be attempting to conceal their sexual orientations. Even though self-presentation bias has not been found to affect judgments of sexual orientation (e.g., Rule et al. 2009a), due to the stigma associated with bisexuality (Eliason 2001), it is conceivable that bisexual targets may sometimes pose or act differently to pass as straight or gay in a non-dating environment (see Goffman 1963; Yoshino 2006). Given its intermediary nature, future studies should also investigate whether bisexual individuals may be able to better conceal their sexual orientation than straight, gay, and lesbian people.

Moreover, it would be informative to consider the sexual orientations of the perceivers. Previous work has shown that gay men are more accurate than straight men in judging sexual orientation from faces (Rule et al. 2007). Perhaps it is possible that bisexuals would be even more discerning, given their presumably greater experience with both groups. In addition, relationship status and dating interest could provide interesting individual differences in the accuracy of judgments of sexual orientation. Future research into these questions may therefore prove enlightening.

In summary, we found that faces of bisexual men and women were effectively perceived as gay and lesbian; however, bisexuals could be differentiated from straight individuals on the basis of their faces alone. Future studies should identify the pathways by which this categorization occurs, as well as the predictive powers of the face in perceptions of sexual orientation. The face may offer insight to the perceptual and psychological realities of bisexual individuals; this study is one first step in that investigation. 


\section{References}

Ambady, N., Bernieri, F. J., \& Richeson, J. A. (2000). Toward a histology of social behavior: Judgmental accuracy from thin slices of the behavioral stream. Advances in Experimental Social Psychology, 32, 201-271.

Ambady, N., Hallahan, M., \& Conner, B. (1999). Accuracy of judgments of sexual orientation from thin slices of behavior. Journal of Personality and Social Psychology, 77, 538-547.

Ambady, N., \& Rosenthal, R. (1992). Thin slices of expressive behavior as predictors of interpersonal consequences: A meta-analysis. Psychological Bulletin, 111, 256-274.

Bar, M., Neta, M., \& Linz, H. (2006). Very first impressions. Emotion, 6, 269-278.

Baumeister, R. F. (2000). Gender differences in erotic plasticity: The female sex drive as socially flexbile and responsive. Psychological Bulletin, 126, 347-374.

Biernat, M., \& Manis, M. (1994). Shifting standards and stereotype-based judgments. Journal of Personality and Social Psychology, 66, 5-20.

Blumstein, P., \& Schwartz, P. (1977). Bisexuality: Some social psychological issues. Journal of Social Issues, 33, 30-34.

Brebner, J. L., Martin, D., \& Macrae, C. N. (2009). Dude looks like a lady: Exploring the malleability of person perception. European Journal of Social Psychology, 39, 1109-1119.

Cass, V. (1984). Homosexual identity: A concept in need of a definition. Journal of Homosexuality, 9, 105-126.

Chandra, A., Mosher, W. D., Copen, C., \& Sionean, C. (2011). Sexual behavior, sexual attraction, and sexual identity in the United States: Data from the 2006-2008 National Survey of Family Growth. National Health Statistics Reports, 36, 1-36.

Choi, Y. S., Gray, H. M., \& Ambady, N. (2005). The glimpsed world: Unintended communication and unintended perception. In R. R. Hassin, J. S. Uleman, \& J. A. Bargh (Eds.), The new unconscious (pp. 309-333). New York: Oxford University Press.

Collins, M. A., \& Zebrowitz, L. A. (1995). The contributions of appearance to occupational outcomes in civilian and military settings. Journal of Applied Social Psychology, 25, 129-163.

Diamond, L. M. (2003). Was it a phase? Young women's relinquishment of lesbian/bisexual identities over a 5-year period. Journal of Personality and Social Psychology, 84, 352-364.

Ekman, P., \& Friesen, W. V. (1969). Nonverbal leakage and clues to deception. Psychiatry, 32, $88-106$.

Eliason, M. (2001). Bi-negativity: The stigma facing bisexual men. Journal of Bisexuality, 1, 137-154.

Gibson, J. J. (1979). The ecological approach to visual perception. Boston: Houghton Mifflin.

Goffman, E. (1963). Stigma: Notes on the management of spoiled identity. Englewood Cliffs: Prentice-Hall.

Goode, E., \& Haber, L. (1977). Sexual correlates of homosexual experience: An exploratory study of college women. Journal of Sex Research, 13, 12-21.

Harker, L., \& Keltner, D. (2001). Expressions of positive emotion in women's college yearbook pictures and their relationship to personality and life outcomes across adulthood. Journal of Personality and Social Psychology, 80, 112-124.

Haselton, M. G., \& Funder, D. (2006). The evolution of accuracy and bias in social judgment. In M. Schaller, J. A. Simpson, \& D. T. Kenrick (Eds.), Evolution and social psychology (pp. 15-37). New York: Psychology Press.

Herek, G. M. (2002). Heterosexuals' attitudes toward bisexual men and women in the United States. Journal of Sex Research, 39, 264-274.

Janus, S., \& Janus, C. (1993). The Janus report on sexual behavior. New York: Wiley.

Johnson, K. L., Gill, S., Reichman, V., \& Tassinary, L. G. (2007). Swagger, sway, and sexuality: Judging sexual orientation from body motion and morphology. Journal of Personality and Social Psychology, 93, 321-324.

Kinsey, A. C., Pomeroy, W. B., \& Martin, C. E. (1948). Sexual behavior in the human male. Philadelphia: W. B. Saunders.

Laumann, E. O., Gagnon, J. H., Michael, R. T., \& Michaels, S. (1994). The social organization of sexuality: Sexual practices in the United States. Chicago: University of Chicago Press.

Levon, E. (2007). Sexuality in context: Variation and the sociolinguistic perception of identity. Language in Society, 36, 533-554.

MacDonald, A. P. (1981). Bisexuality: Some comments on research and theory. Journal of Homosexuality, $6,21-35$.

Macrae, C. N., \& Bodenhausen, G. V. (2001). Social cognition: Categorical person perception. British Journal of Psychology, 92, 239-255. 
McArthur, L. Z., \& Baron, R. M. (1983). Toward an ecological theory of social perception. Psychological Review, 90, 215-238.

Miller, G. F., \& Todd, P. M. (1998). Mate choice turns cognitive. Trends in Cognitive Sciences, 2, 190-198.

Mueller, U., \& Mazur, A. (1996). Facial dominance of West Point cadets as a predictor of later military rank. Social Forces, 74, 823-850.

Nicholas, C. L. (2004). Gaydar: Eye-gaze as identity recognition among gay men and lesbians. Sexuality and Culture, 8, 60-86.

Peplau, L. A. (2003). Human sexuality: How do men and women differ? Current Directions in Psychological Science, 12, 37-40.

Richeson, J. A., \& Trawalter, S. (2005). On the categorization of admired and disliked exemplars of admired and disliked racial groups. Journal of Personality and Social Psychology, 89, 517-530.

Rieger, G., Linsenmeier, J. A. W., Gygax, L., \& Bailey, J. M. (2008). Sexual orientation and childhood gender nonconformity: Evidence from home videos. Developmental Psychology, 44, 46-58.

Rieger, G., Linsenmeier, J. A. W., Gygax, L., Garcia, S., \& Bailey, J. M. (2010). Dissecting "Gaydar": Accuracy and role of masculinity-femininity. Archives of Sexual Behavior, 39, 124-140.

Rosenthal, R., \& Jacobson, L. (1968). Pygmalion in the classroom. New York: Holt, Rinehart, \& Winston.

Rudd, N. A. (1996). Appearance and self-presentation research in gay consumer cultures: Issues and impact. Journal of Homosexuality, 31,109-134.

Rule, N. O., \& Ambady, N. (2008). Brief exposures: Male sexual orientation is accurately perceived at 50-ms. Journal of Experimental Social Psychology, 44, 1100-1105.

Rule, N. O., \& Ambady, N. (2011). Judgments of power from college yearbook photos and later career success. Social Psychological and Personality Science, 2, 154-158.

Rule, N. O., Ambady, N., Adams, R. B., Jr, \& Macrae, C. N. (2007). Us and them: Memory advantages in perceptually ambiguous groups. Psychonomic Bulletin \& Review, 14, 687-692.

Rule, N. O., Ambady, N., Adams, R. B., Jr, \& Macrae, C. N. (2008). Accuracy and awareness in the perception and categorization of male sexual orientation. Journal of Personality and Social Psychology, 95, 1019-1028.

Rule, N. O., Ambady, N., \& Hallett, K. (2009a). Female sexual orientation is perceived accurately, rapidly, and automatically from the face and its features. Journal of Experimental Social Psychology, 45, 1245-1251.

Rule, N. O., Macrae, C. N., \& Ambady, N. (2009b). Ambiguous group membership is extracted automatically from faces. Psychological Science, 20, 441-443.

Rule, N. O., Rosen, K. S., Slepian, M. L., \& Ambady, N. (2011). Mating interest improves women's accuracy in judging male sexual orientation. Psychological Science, 22, 881-886.

Savin-Williams, R. C., \& Ream, G. L. (2007). Prevalence and stability of sexual orientation components during adolescence and young adulthood. Archives of Sexual Behavior, 36, 386-394.

Schaller, M. (2008). Evolutionary bases of first impressions. In N. Ambady \& J. J. Skowronski (Eds.), First impressions (pp. 15-34). New York: Guilford Press.

Sedikides, C., \& Skowronski, J. J. (2009). Social cognition and self-cognition: Two sides of the same evolutionary coin? European Journal of Social Psychology, 39, 1245-1249.

Smith, E. A., Munson, B., \& Hall, K. C. (2008). Rethinking the meaning of Minnesotan [a]: Sexual orientation or personal well being? Oral presentation at the conference on New Ways of Analyzing Variation (NWAV). Texas: Houston.

Smyth, R., Jacobs, G., \& Rogers, H. (2003). Male voices and perceived sexual orientation: An experimental and theoretical approach. Language and Society, 32, 329-350.

Sylva, D., Rieger, G., Linsenmeier, J. A., \& Bailey, J. M. (2010). Concealment of sexual orientation. Archives of Sexual Behavior, 39, 141-152.

Thornhill, R., \& Gangestead, S. W. (1996). The evolution of human sexuality. Trends in Ecology \& Evolution, 11, 98-102.

Wagner, H. L. (1993). On measuring performance in category judgment studies of nonverbal behavior. Journal of Nonverbal Behavior, 17, 3-28.

Weinberg, M. S., Williams, C. J., \& Pryor, D. W. (1995). Dual attraction: Understanding bisexuality. New York: Oxford University Press.

Wright, D. B., \& Sladden, B. (2003). An own gender bias and the importance of hair in face recognition. Acta Psychologica, 114, 101-114.

Wright, D. B., \& Stroud, J. N. (2002). Age differences in lineup identification accuracy: People are better with their own age. Law and Human Behavior, 26, 641-654.

Yoshino, K. (2006). Covering: The hidden assault on our civil rights. New York: Random House.

Zebrowitz, L. A. (1997). Reading faces: Window to the soul?. Boulder, CO: Westview. 
Zebrowitz, L. A., \& McDonald, S. M. (1991). The impact of litigants' baby-facedness and attractiveness on adjudications in small claims courts. Law and Human Behavior, 15, 603-623.

Zebrowitz, L. A., \& Montepare, J. (2006). The ecological approach to person perception: Evolutionary roots and contemporary offshoots. In M. Schaller, J. A. Simpson, \& D. T. Kenrick (Eds.), Evolution and social psychology (pp. 81-113). New York: Psychology Press. 